\title{
Article \\ Old Parasitoids for New Mealybugs: Host Location Behavior and Parasitization Efficacy of Anagyrus vladimiri on Pseudococcus comstocki
}

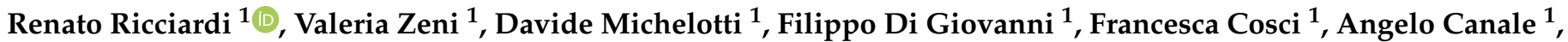 \\ Lian-Sheng Zang ${ }^{2}$, Andrea Lucchi ${ }^{1}$ and Giovanni Benelli ${ }^{1, *(D)}$ \\ 1 Department of Agriculture, Food and Environment, University of Pisa, via del Borghetto 80, 56124 Pisa, Italy; \\ renato_ricciardi@hotmail.it (R.R.); valeriazeni93@gmail.com (V.Z.); d.michelotti1@studenti.unipi.it (D.M.); \\ aphelocheirus@gmail.com (F.D.G.); francesca.cosci1@virgilio.it (F.C.); angelo.canale@unipi.it (A.C.); \\ andrea.lucchi@unipi.it (A.L.) \\ 2 Key Laboratory of Green Pesticide and Agricultural Bioengineering, Guizhou University, \\ Guiyang 550025, China; lsz0415@163.com \\ * Correspondence: giovanni.benelli@unipi.it; Tel.: +39-050-221-6141
}

\section{check for}

updates

Citation: Ricciardi, R.; Zeni, V.; Michelotti, D.; Di Giovanni, F.; Cosci, F.; Canale, A.; Zang, L.-S.; Lucchi, A.; Benelli, G. Old Parasitoids for New Mealybugs: Host Location Behavior and Parasitization Efficacy of Anagyrus vladimiri on Pseudococcus comstocki. Insects 2021, 12, 257. https://doi.org/10.3390/ insects12030257

Academic Editor: Annette Reineke

Received: 5 February 2021

Accepted: 11 March 2021

Published: 18 March 2021

Publisher's Note: MDPI stays neutral with regard to jurisdictional claims in published maps and institutional affiliations.

Copyright: (c) 2021 by the authors. Licensee MDPI, Basel, Switzerland. This article is an open access article distributed under the terms and conditions of the Creative Commons Attribution (CC BY) license (https:/ / creativecommons.org/licenses/by/ $4.0 /)$.
Simple Summary: Anagyrus vladimiri has been widely employed as a biological control agent (BCA) against the vine mealybugs Planococcus ficus but the knowledge about its employment against other mealybug species is limited. In this study, we investigated the potential efficacy of A. vladimiri for Pseudococcus comstocki management, considering the increasing threat represented by this mealybug pest in Mediterranean vineyards and fruit orchards. No-choice and two-choice tests were conducted to quantify parasitoid behavior against $P$. ficus and $P$. comstocki. Our results pointed out that $A$. vladimiri successfully parasitized both pests, showing no host preference between the two species. Our observations highlight that this parasitoid can be successfully deployed as BCA against P. comstocki populations.

Abstract: The Comstock mealybug, Pseudococcus comstocki (Hemiptera: Pseudococcidae) is a primary pest of orchards in the North and Northwest of China. This pest appeared recently in Europe, including Italy, where it is infesting mainly vineyards as well as apple and pear orchards. The present study investigated the efficacy of Anagyrus vladimiri, a known biological control agent (BCA) of Planococcus ficus, on P. comstocki to evaluate a potential use for the management of this new pest. No-choice tests were conducted to quantify the parasitoid behavior against $P$. ficus and $P$. comstocki. The parasitoid successfully parasitized both species (parasitization rate: $51 \%$ and $67 \%$ on $P$. comstocki and P. ficus, respectively). The A. vladimiri developmental time (19.67 \pm 1.12 vs. $19.70 \pm 1.07$ days), sex ratio (1.16 \pm 1.12 vs. $1.58 \pm 1.07)$ and hind tibia length of the progeny showed no differences when $P$. comstocki and $P$. ficus, respectively, were exploited as hosts. Two-choice tests, conducted by providing the parasitoid with a mixed population of $P$. ficus and $P$. comstocki, showed no host preference for either of the two mealybug species (23 vs. 27 first choices on P. comstocki and P. ficus, respectively). The parasitization rate $(61.5 \%$ and $64.5 \%$ in $P$. comstocki and $P$. ficus, respectively) did not differ between the two hosts. Overall, our study adds basic knowledge on parasitoid behavior and host preferences and confirms the use of this economically important encyrtid species as an effective BCA against the invasive Comstock mealybug.

Keywords: biological control; Encyrtidae; parasitization behavior; parasitoid fitness; Planococcus ficus; Pseudococcidae

\section{Introduction}

The Comstock mealybug, Pseudococcus comstocki (Kuwana) (Hemiptera: Pseudococcidae), is widely recognized as an important insect pest of fruit trees, especially pear trees, in 
many fruit-producing regions of the world, with special reference to North and Northwest China [1]. Its importance as an emerging pest of fruit, vineyard and ornamental crops in European countries, including Italy, is increasing [2,3] (Parrilli M. and Burgio G, unpubl. data). The nymphs and adult females strongly inhibit the growth and morphogenesis of fruit trees, mainly by feeding on buds, twigs, leaves, fruits, and rootlets, resulting in twig and shoot swelling, longitudinal cracking, abnormal fruit development and production of a large quantity of honeydew, thus causing major economic losses [1,4]. Several studies have been conducted to increase the knowledge about the biology of this mealybug pest, looking for effective control strategies [5,6]. Xu et al. [7] investigated the influence of temperature on $P$. comstocki population, highlighting that $26^{\circ} \mathrm{C}$ was the optimal temperature for population growth while low (below $17^{\circ} \mathrm{C}$ ) and high (above $29^{\circ} \mathrm{C}$ ) temperatures reduced the population growth rate. Jeon et al. [8] also investigated the incorporation of temperature in the development of forecasting models for timing insecticide applications against $P$. comstocki.

Recently, increasing attention has been given to finding effective and ecologically acceptable methods for controlling Comstock mealybugs. Within the Integrated Pest Management (IPM) scenario, biological control agents (BCAs) such as predatory coccinellid beetles, e.g., Cryptolaemus montrouzieri (Coleoptera: Coccinellidae) [9] as well as parasitic Hymenoptera, could provide useful tools. In this framework, Malausa et al. [10] evaluated Allotropa burrelli Muesebeck (Hymenoptera: Platygastridae) and Acerophagus malinus (Gahan) (Hymenoptera: Encyrtidae) for the control of P. comstocki in France. An earlier study aimed at defining the complex of $P$. comstocki parasitoids in Italy includes two other species, Acerophagus maculipennis (Mercet) (Hymenoptera: Encyrtidae) and Anagyrus sp. near pseudococci (Girault) (Hymenoptera: Encyrtidae), recently re-described as Anagyrus vladimiri Triapitsyn [4,11]. The latter is widely known for its efficacy against other important mealybug species, such as the grapevine mealybug, Planococcus ficus (Signoret) (Hemiptera: Pseudococcidae), which recently led to its wide-scale adoption in more than 800 hectares of high-valued organic vineyards (i.e., Bolgheri area, Tuscany, Italy) [12].

Despite the earlier records of $A$. vladimiri parasitization on $P$. comstocki, no quantitative data are available to shed light on the effectiveness of this encyrtid against the Comstock mealybug. To the best of our knowledge, little is known about $A$. vladimiri host preferences and suitability when foraging on $P$. comstocki mixed with other mealybug species, such as the grapevine mealybug. The present study aims to quantify, the oviposition behavior of a mass-reared commercially available strain of $A$. vladimiri attacking young females of $P$. comstocki. Furthermore, host preferences [13] of $A$. vladimiri for the above-mentioned mealybug species over its potential "optimal" host P. ficus, were evaluated, both in nochoice and two-choice conditions. The host suitability of the Comstock mealybug for the successful development of $A$. vladimiri was assessed, shedding light on the potential of this encyrtid species for real-world biocontrol attempts.

\section{Materials and Methods}

\subsection{Insect Rearing and General Observations}

Insect rearing and experimental assays were conducted in laboratory conditions at $23 \pm 1{ }^{\circ} \mathrm{C}, 45 \pm 5 \% \mathrm{RH}$ and a 14:10 (L:D) photoperiod. A commercial strain of A. vladimiri, as well as its routine host P. ficus, were maintained as described by Romano et al. [14]. A field strain of P. comstocki, originally collected in the Emilia-Romagna region (Central Italy), was reared on potato sprouts, a common food substrate for mealybugs, as detailed by Islam and Copland [15]. The whole rearing apparatus was placed in dark rearing cages $(180 \times 90 \times 90 \mathrm{~cm})\left(\right.$ Bugdorm ${ }^{\circledR}$, Megaview Science, Taiwan $)$.

All experiments were carried out using 2-5-day-old $A$. vladimiri mated females fed ad libitum with a solution of honey and water $(1: 1, w: v)$ and never exposed to mealybug hosts before testing [15]. 


\subsection{Oviposition Behavior, Host Preferences, Host Suitability and Quality of the Parasitoid Progeny}

The host-seeking and oviposition behavior of $A$. vladimiri was quantified on P. comstocki young females following the method by Chong and Oetting [16] with a few modifications. The host-seeking and oviposition behavior of A. vladimiri on P. comstocki were observed using a new Petri dish for each test (hereafter, the arena, diameter $35 \mathrm{~mm}$ ) under uniform daylight conditions. Two kinds of experiments were conducted: no-choice and two-choice tests, detailed below.

\subsubsection{No-Choice Tests}

In the no-choice test, a single $A$. vladimiri mated female was provided with $8 P$. comstocki (mean \pm SD; length $x$ width: $2.65 \pm 0.38 \times 1.57 \pm 0.29 \mathrm{~mm}$; weight: $0.0012 \pm 0.0003 \mathrm{~g}$ ) or 8 P. ficus young females (mean $\pm \mathrm{SD}$; length $\mathrm{x}$ width: $2.95 \pm 0.14 \times 1.78 \pm 0.17 \mathrm{~mm}$; weight: $0.0013 \pm 0.0002 \mathrm{~g}$ ). To easily track each mealybug during the behavioral assays, each insect position was noted on a separate paper sheet before the experiment, and further position changes were noted by an observer [16]. To reduce the potential influence of visual cues surrounding the testing arena on the insect behavior, the observer was dressed in a white coat, and the arena was surrounded by a white wall of filter paper (Whatman no. 1, height $30 \mathrm{~cm}$ ) [17].

After introducing the parasitoid in the experimental arena, the occurrence and duration (s) of the following displays were noted and used to construct an ethogram: (i) latency (i.e., the time spent by $A$. vladimiri remaining stationary before starting host searching), (ii) host searching (i.e., the parasitoid walks around performing antennal tapping), (iii) host encounter (i.e., the parasitoid detects a potential host and stops close to it), (iv) antennal examination (i.e., the parasitoid remains still and performs antennal tapping on the host), (v) ovipositor probing (i.e., the parasitoid swiftly inserts its ovipositor in the host, if the event lasts more than $10 \mathrm{~s}$, an oviposition succeeds; Benelli G., personal observation), (vi) and oviposition (i.e., the parasitoid keeps the ovipositor inside the host's body, laying an egg) [16]. (vii) Host dragging during oviposition (i.e., the host moves away dragging the ovipositing parasitoid around), as well as (vii) host defensive displays (i.e., the mealybug performs quick body movements against the parasitoid), were also recorded. The possible occurrence and duration of host feeding behavior was noted, following Bokonon-Ganta et al. [18]. The number of mealybugs encountered, examined, and probed by each parasitic wasp within the observation period was noted [19]. The observation period was $20 \mathrm{~min}$; A. vladimiri females not starting any of the host-seeking displays detailed above within $10 \mathrm{~min}$ were discarded from the study [16]. Each no-choice observation was replicated 50 times.

Furthermore, we assessed the host suitability of $P$. comstocki young females for the development and survival of $A$. vladimiri, and the quality of progeny. Both in the $P$. comstock $i$ and $P$. ficus no-choice experiments, the parasitoid was left in the arena for $24 \mathrm{~h}$ after the 20-min observation period, allowing the female to parasitize mealybugs. Then, the exposed hosts were monitored daily for 30 days using a stereomicroscope, noting the parasitism rate (i.e., \% of mummified mealybugs) and development duration (i.e., the period between A. vladimiri parasitization and adult emergence). The number and sex ratio of $A$. vladimiri offspring on the two hosts were also determined [16].

Hind tibia length was used as a surrogate for body length [19]. Newly emerged parasitoids were stored in 70\% ethanol $24 \mathrm{~h}$ after their emergence. Their left hind tibia was removed and mounted on a microscope slide. The left hind tibia length of all adult parasitoids was measured with an ocular micrometer at $60 \times$ to investigate the effect of host species on the fitness of parasitoids [16].

\subsubsection{Two-Choice Tests}

In the two-choice tests, a single $A$. vladimiri female was exposed to a mixed population of $P$. comstocki and $P$. ficus young females, transferring 4 individuals per species into 
the experimental arena. The $P$. comstocki and $P$. ficus young females were alternately distributed close to the borders of the area, equally distanced each other. The $A$. vladimiri female was released in the center of the testing arena, equally distanced from all the mealybug individuals.

Following the method reported above for "No-choice tests", after the introduction of an $A$. vladimiri female into the arena, the parasitoid was visually tracked by an observer, and the following parameters were noted: (i) the $A$. vladimiri first choice (i.e., which mealybug was first approached with a successful parasitization during the observation time), (ii) the number of successfully parasitized hosts within the observation time, and (iii) the oviposition duration on the selected host (if multiple oviposition acts occurred, only the duration of the oviposition following the first choice on a given host was noted). For each replicate, the observation time was $20 \mathrm{~min}$; 50 replicates were carried out. A. vladimiri females not starting any of the host-seeking displays within $10 \mathrm{~min}$ were removed from the study [16].

Furthermore, in each replicate $A$. vladimiri was left in the arena for $24 \mathrm{~h}$ after the $20 \mathrm{~min}$ observations period direct observation, allowing the parasitization of the mealybugs of both species. The successful parasitization of the exposed hosts was monitored daily for 30 days, noting the parasitism rate on $P$. comstocki and $P$. ficus (i.e., \% of mummified mealybugs).

\subsection{Statistical Analysis}

In no-choice behavioral assays, differences in the duration of the following behavioral displays, i.e., latency, host searching, antennal tapping, probing and oviposition on the two hosts were evaluated by a General Linear Mixed Model (GLMM) with one factor [20]: $\mathrm{y}_{\mathrm{iw}}=\mu+\mathrm{H}_{\mathrm{i}}+\mathrm{ID}_{\mathrm{w}}+\mathrm{e}_{\mathrm{iw}}$, in which $\mathrm{y}_{\mathrm{iw}}$ is the observation, $\mu$ is the overall mean, $\mathrm{H}_{\mathrm{i}}$ is the $i$-th fixed effect of the tested mealybug host $(i=1-2), \mathrm{ID}_{\mathrm{w}}$ is the $w$-th random effect of the parasitoid over repeated host searching and parasitization events $(w=1-50)$ and $\mathrm{e}_{\mathrm{iw}}$ the residual error; $p<0.05$ was used to assess significance of differences between means.

Differences in the number of parasitoids displaying host encounter, antennal tapping, probing, oviposition, host dragging, kicking and superparasitization on the two mealybug hosts and parasitoid emergence were evaluated using the Kruskal-Wallis test $(p=0.05)$, while parasitization rates were evaluated using the Wilcoxon test $(p=0.05)$.

Differences in the hind tibia length of parasitoids emerged from the two hosts were evaluated using a weighted generalized linear model (GLZ, Poisson distribution) with one fixed factor [21]: $y=X \beta+\varepsilon$ where $y$ is the vector of the observations (the hind tibia length), $X$ is the incidence matrix, $\beta$ is the vector of the fixed effect (the mealybug host) and $\varepsilon$ is the vector of the random residual effects.

In two-choice tests, differences between the number of $A$. vladimiri first choices when parasitizing $P$. comstock $i$ vs. P. ficus were evaluated using a likelihood ratio $\chi^{2}$ tests, with Yates' correction [22]. Furthermore, differences in the number of successfully parasitized hosts within $20 \mathrm{~min}$ and $24 \mathrm{~h}$ on the two mealybug hosts were analyzed with a Wilcoxon test $(p=0.05)$. Differences in the $A$. vladimiri oviposition duration on the two mealybug hosts were evaluated using the Kruskal-Wallis test $(p=0.05)$. JMP 9 (SAS) was used for all the analyses.

\section{Results}

\subsection{No-Choice Tests}

In no-choice tests, when $A$. vladimiri encountered a potential host, it started antennal tapping on the mealybug body to accept or reject the host (Figure 1). If the host was of interest, A. vladimiri turned itself, everted the ovipositor and attempted to probe. 


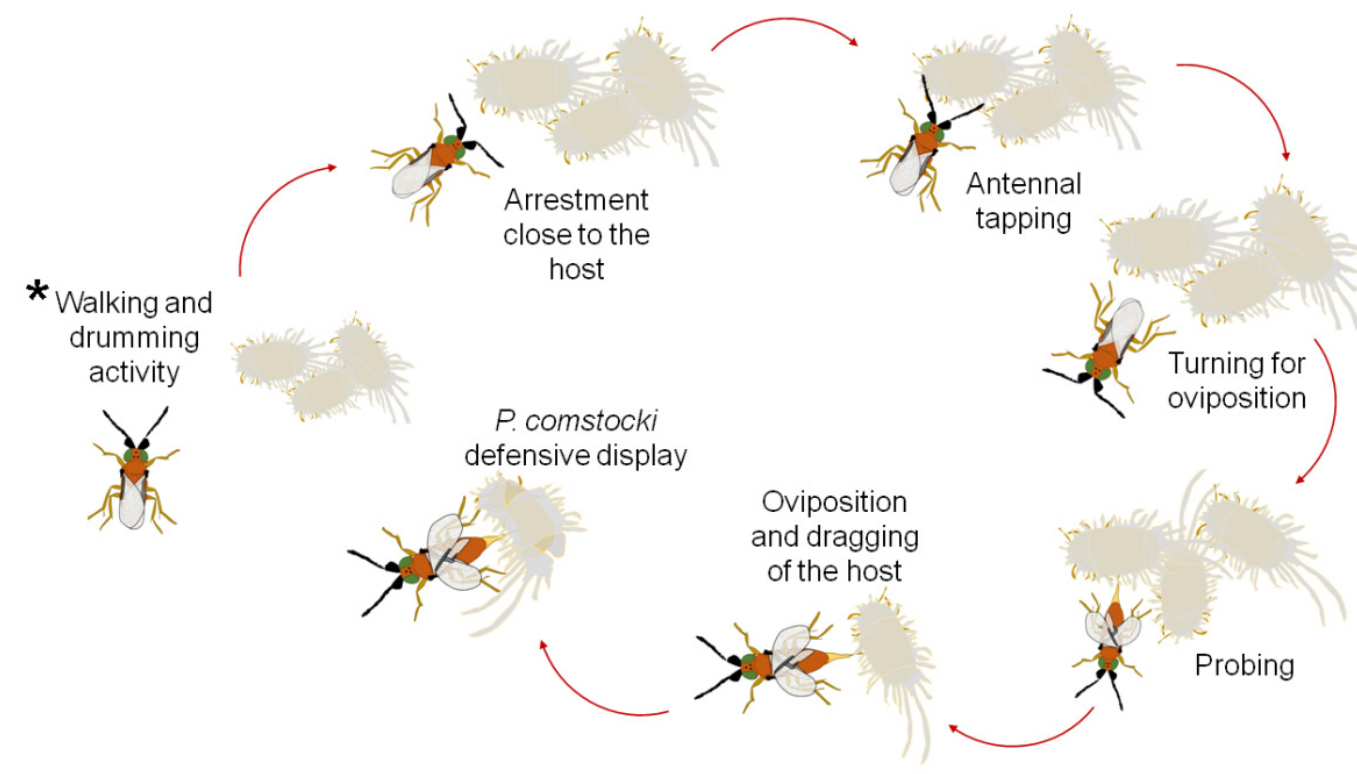

Figure 1. Host searching and parasitization behavior of Anagyrus vladimiri towards Pseudococcus comstocki (the asterisk indicates where the behavioral sequence begins).

If the host was not suitable, the parasitoid moved away and started again the hostseeking activity. Oviposition occurred after a positive probing outcome, usually on the dorso-lateral side of the host (Figure 2).

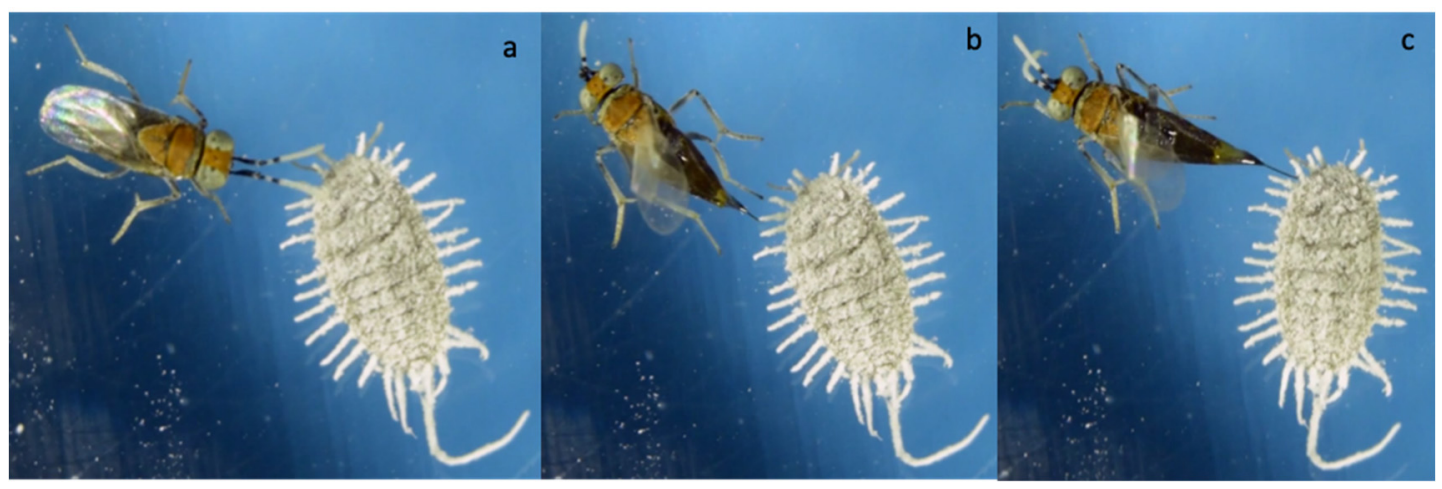

Figure 2. Key behavioral displays performed by Anagyrus vladimiri during host searching and parasitization on Pseudococcus comstocki: (a) antennal tapping, (b) probing, and (c) oviposition.

Overall, the displays composing the host-seeking and parasitization behavior of A. vladimiri on P. comstocki were walking and drumming activity, arrestment close to the host, antennal tapping, probing, oviposition, and host dragging. In addition, a peculiar host defensive behavior was noted, i.e., a fast abdominal rocking movement against the parasitoid (kicking), coupled or not with the production of a viscous secretion against the parasitoid to impair its wings $[23,24]$. Host feeding behavior was not observed.

The ethograms of $A$. vladimiri parasitizing P. comstocki (Figure 3a) and P. ficus (Figure 3b) were built analyzing the first host-seeking and oviposition event observed in fifty $A$. vladimiri females. 
(a)

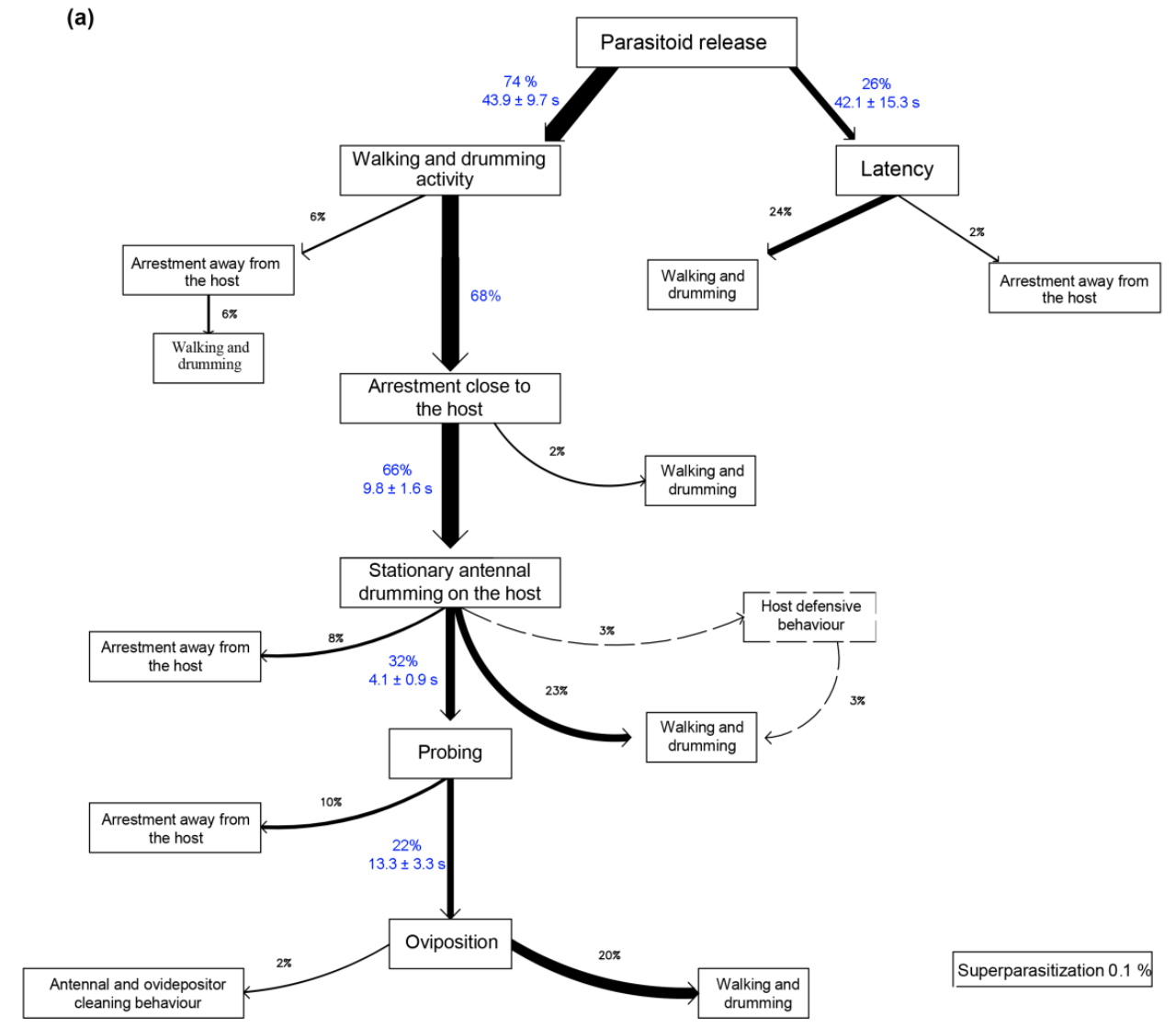

(b)

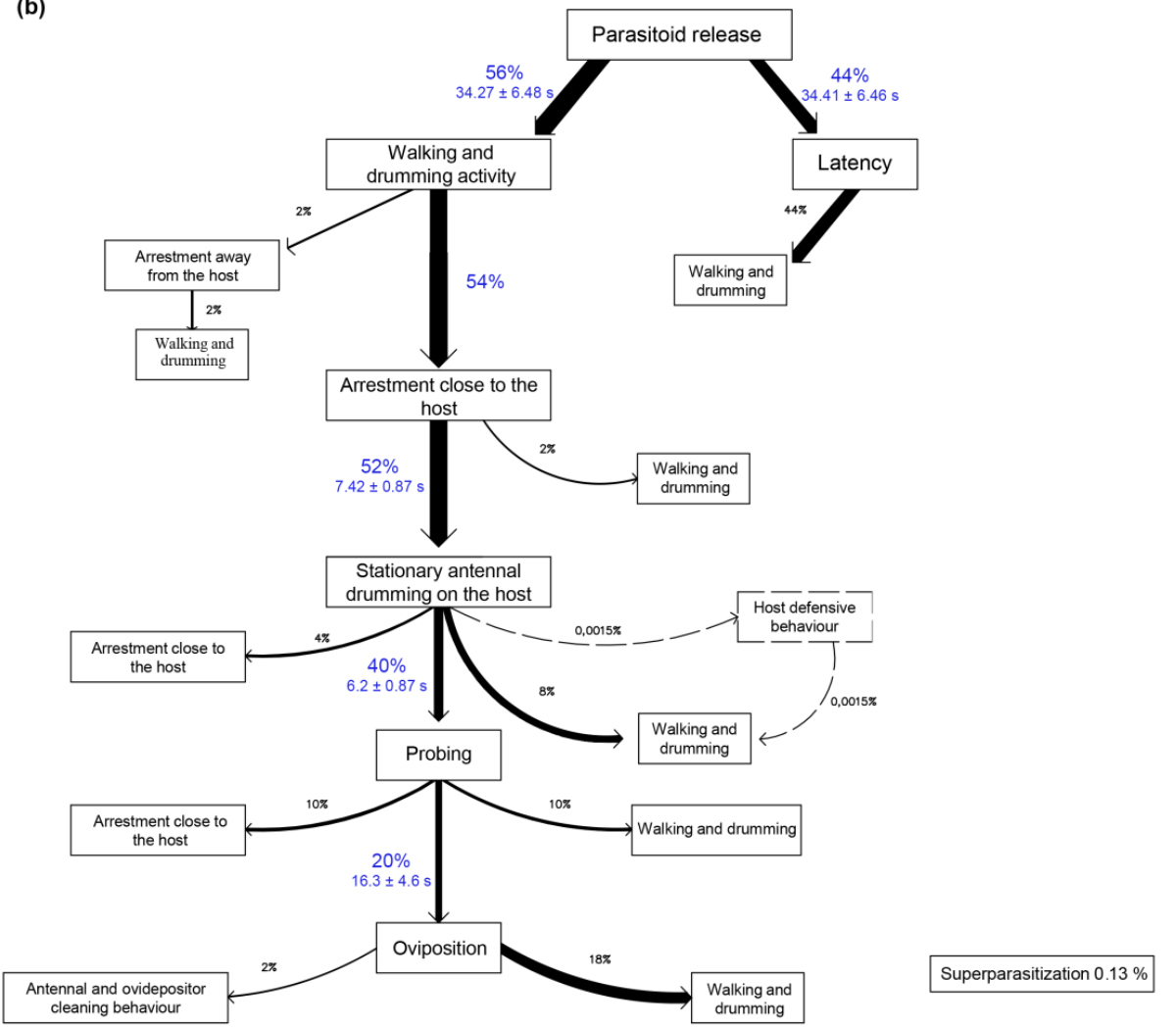

Figure 3. Quantitative analysis of behavioral displays performed by Anagyrus vladimiri parasitizing Pseudococcus comstocki (a) and Planococcus ficus (b). (\% values indicate the percentage of individuals performing a given display out of the total number of individuals in the experiment; when it was possible to quantify it, the duration of each display is provided in seconds (s) (means $\pm \mathrm{SD}$ ); Superparasitism (\%) of each host is provided in the lower right corner of each figure). 
As detailed in Figure 3, A. vladimiri showed comparable host seeking and oviposition sequences towards both mealybug hosts. However, in our no-choice tests, A. vladimiri detected a slightly higher number of $P$. comstocki individuals over $P$. ficus ( $68 \%$ vs. $54 \%$, respectively) although this does not mean that one was detected more than the other. Most of the selected hosts were subjected to antennal examination, lasting less than $10 \mathrm{~s}$ on both hosts. Probing was observed in $32 \%$ of parasitoids attacking P. comstocki, while probing on $P$. ficus was $40 \%$. The oviposition rate was $22 \%$ on P. comstocki and $20 \%$ on $P$. ficus. The above-described host defensive behavior showed by $P$. comstocki and $P$. ficus against $A$. vladimiri was observed in $3 \%$ and $0.0015 \%$ of the parasitoid-host interactions, respectively. A. vladimiri superparasitization acts occurred on both hosts with a comparable rate (P. comstocki $0.1 \%$ and $P$. ficus $0.13 \%$ ).

To understand the parasitization efficiency of $A$. vladimiri towards $P$. comstocki and $P$. ficus, the above-mentioned behavioral displays were compared in terms of duration (s) and frequency (no. of acts). Concerning duration, results showed a significant difference for latency $\left(F_{1,58}=6.71, p=0.0120\right)$, host searching $\left(F_{1,73}=3.9, p=0.05\right)$, antennal tapping $\left(F_{1,84}=18.9, p<0.0001\right)$ and oviposition $\left(F_{1,107}=3.75, p<0.0001\right)$. As a general trend, the duration of these displays was longer in P. ficus than in P. comstocki. There was no significant difference in probing behavior between the two species $\left(F_{1,93}=3.75, p=0.056\right)$ (Figure 4).

The frequency of behavioral displays performed by A. vladimiri approaching its host in no-choice tests highlighted some differences about host searching $\left(\chi^{2}=11.17\right.$, d.f. $=1$, $p=0.0008)$, encounter $\left(\chi^{2}=6.31\right.$, d.f. $\left.=1, p=0.012\right)$, antennal tapping $\left(\chi^{2}=4.38, d . f .=1\right.$, $p=0.0362)$, probing $\left(\chi^{2}=12.4, d . f .=1, p=0.0004\right)$, oviposition $\left(\chi^{2}=9.95, d . f .=1, p=0.0016\right)$ and host defensive behavior $\left(\chi^{2}=4.77, d . f .=1, p=0.029\right)$. However, comparing latency $\left(\chi^{2}=0.86\right.$, d.f. $\left.=1, p=0.35\right)$, host dragging $\left(\chi^{2}=0.0085\right.$, d.f. $\left.=1, p=0.92\right)$ and superparasitization $\left(\chi^{2}=3.15, d . f .=1, p=0.076\right)$, the results showed no significant differences between $P$. comstocki and $P$. ficus (Figure 5).

The parasitization rate, percentage of emerged parasitoids, developmental time and sex ratio of $A$. vladimiri developed on $P$. comstock $i$ were compared with those from wasps developed on $P$. ficus (Figure 6). Significant differences between the percentage of parasitized hosts were found $\left(\chi^{2}=11.808, d . f .=1, p=0.0006\right)$ (Figure 6). The number of parasitoids emerged from the two hosts was not statistically different $\left(\chi^{2}=0.141, d . f .=1, p=0.707\right)$.

On the other hand, no significant difference in the developmental time of the offspring of A. vladimiri from the hosts was found $\left(\chi^{2}=0.088, d . f .=1, p=0.7675\right)$ (Figure 7). The first adult emerged after 17 days from $P$. comstocki (with a mean emergence time of $19.67 \pm 1.12$ (mean \pm SD) ) and 18 days from $P$. ficus (with a mean emergence time of $19.70 \pm 1.07$ $($ mean $\pm \mathrm{SD})$ ). Moreover, no difference in the sex ratio was noted between parasitoid progeny emerging from $P$. comstocki and $P$. ficus (adult sex ratio (ASR): 1.16 and 1.58 for female $P$. comstocki and $P$. ficus, respectively).

The length of the hind tibia of emerged $A$. vladimiri was used as a surrogate of body length to evaluate the fitness of the offspring [19]. No significant difference was found between the two hosts $\left(\chi^{2}=0.12\right.$, d.f. $=1, p=0.720$ ) (Figure 8), confirming that P. comstocki is a highly suitable host for $A$. vladimiri. 
(a)

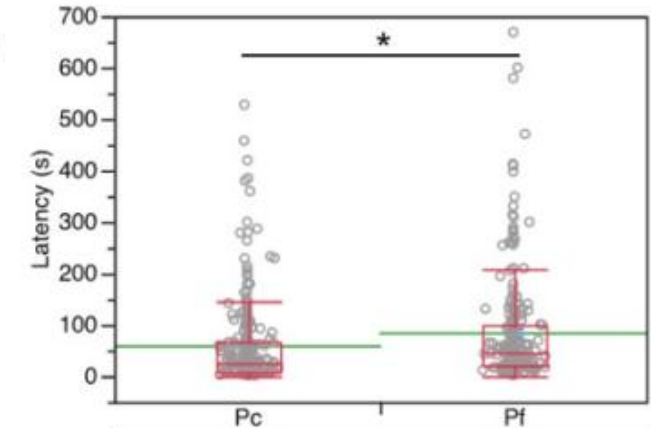

(b)

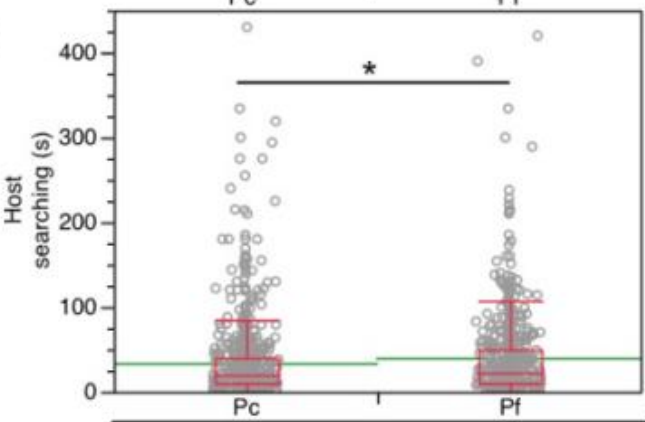

(c)

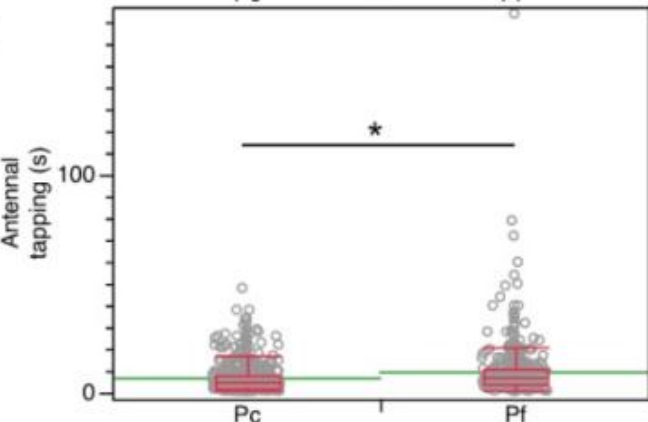

(d)

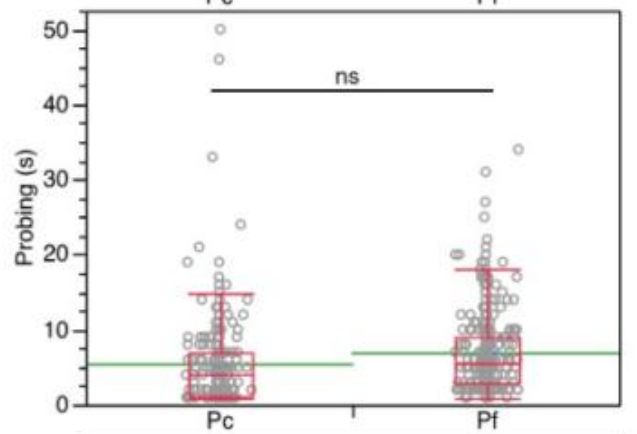

(e)

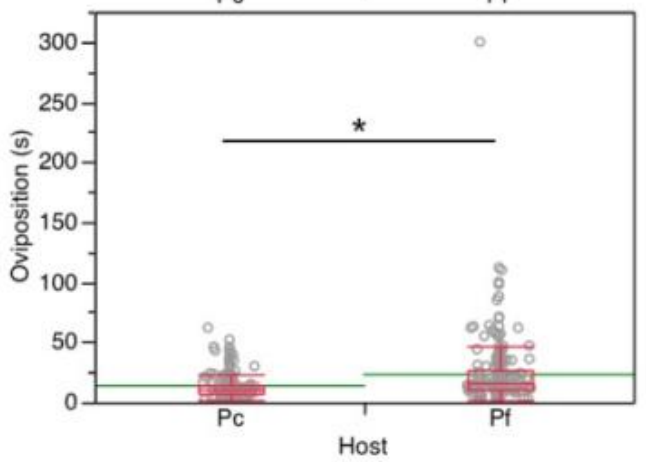

Figure 4. Time spent by Anagyrus vladimiri during (a) latency, (b) host searching, (c) antennal tapping, (d) probing, and (e) oviposition displays in no-choice tests carried out on Pseudococcus comstocki (Pc) and Planococcus ficus (Pf). Each box plot indicates the median (central line) and its range of dispersion (lower and upper quartiles and outliers); green lines indicate the means. Asterisks indicate significant differences (GLM, $p<0.05) ; \mathrm{ns}=$ not significant. 
(a)
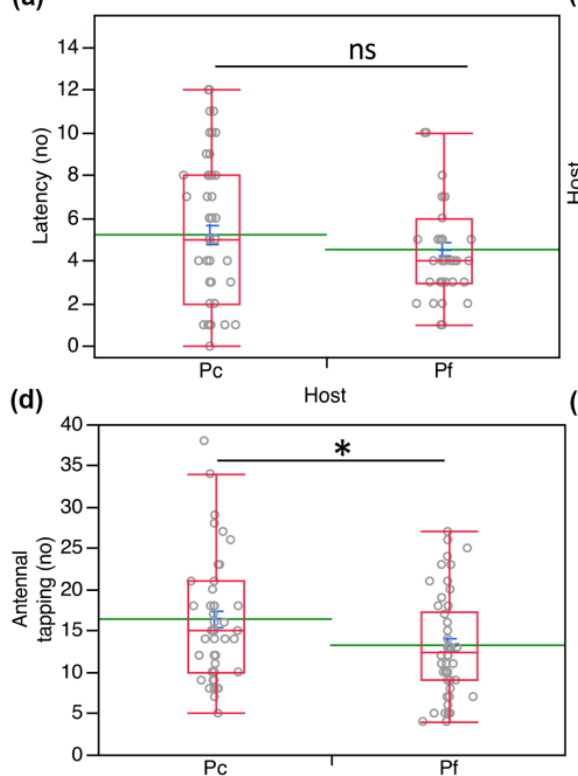

(g)

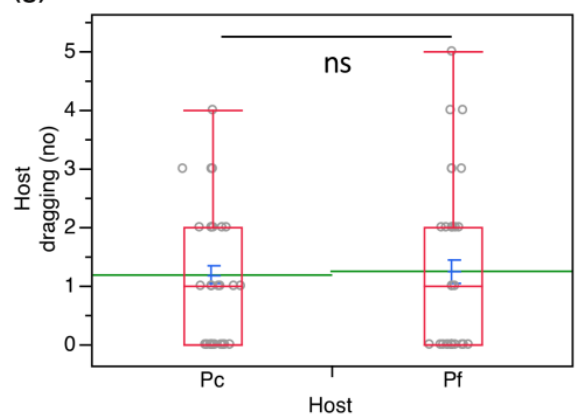

(b)

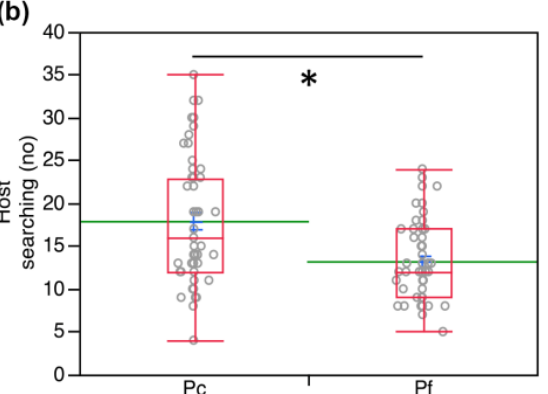

(e)

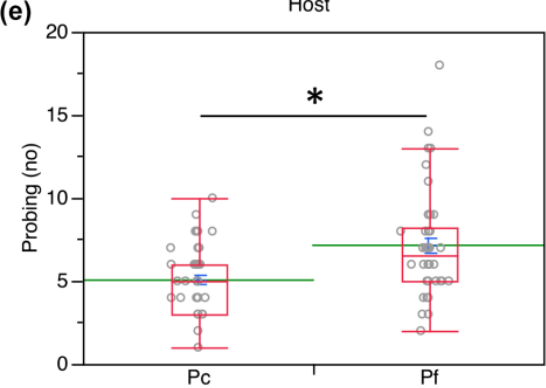

(h)

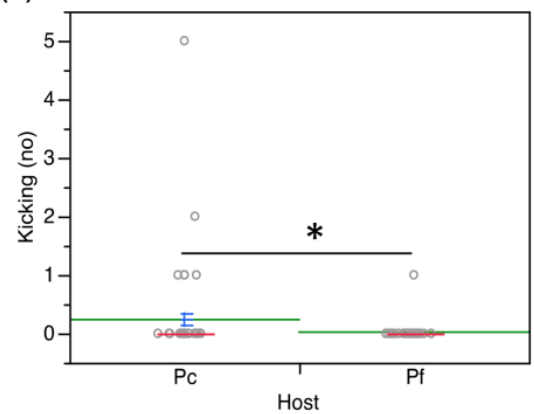

(c)

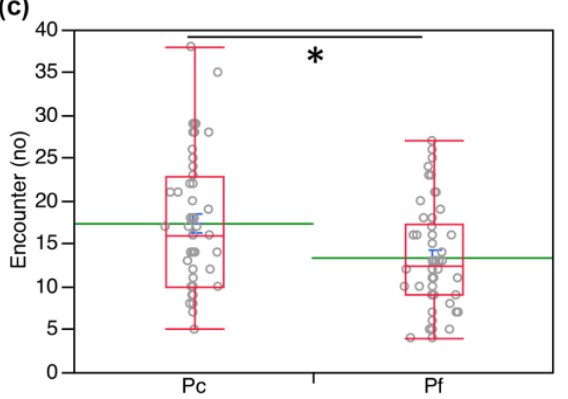

(f)

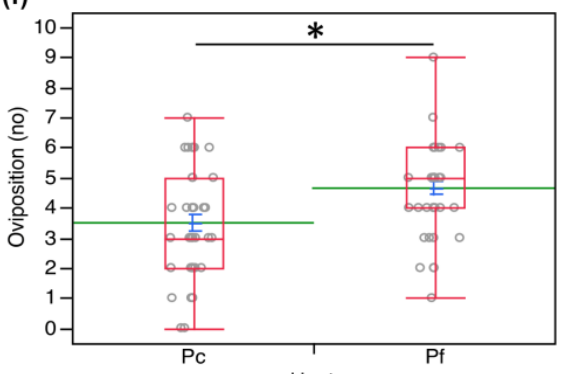

(i)

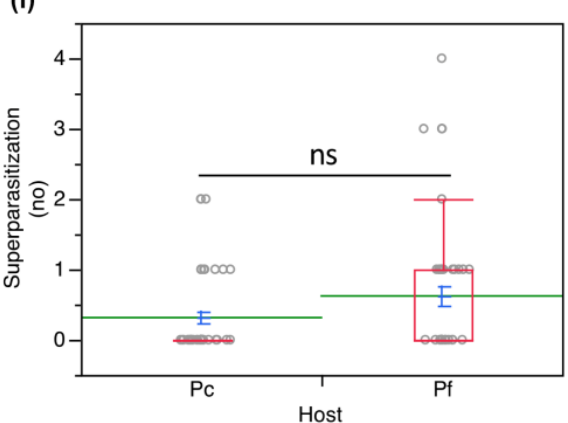

Figure 5. Frequency (no.) of different behavioral parameters performed by Anagyrus vladimiri approaching Pseudococcus comstocki (Pc) and Planococcus ficus (Pf) in no-choice tests: (a) latency, (b) host searching, (c) host encounter, (d) antennal tapping, (e) probing, (f) oviposition, (g) host dragging, (h) kicking (fast abdominal rocking movement against the parasitoid), and (i) superparasitization. Each box plot indicates the median (central line) and its range of dispersion (lower and upper quartiles and outliers); green lines indicate the means, while light blue T-bars indicate standard errors. Asterisks indicate significant differences (Kruskal-Wallis test, $p<0.05)$, ns = not significant.

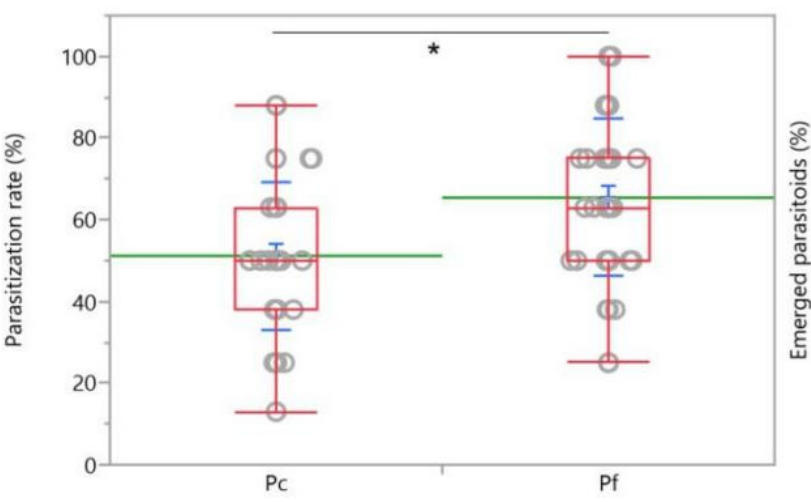

(a)

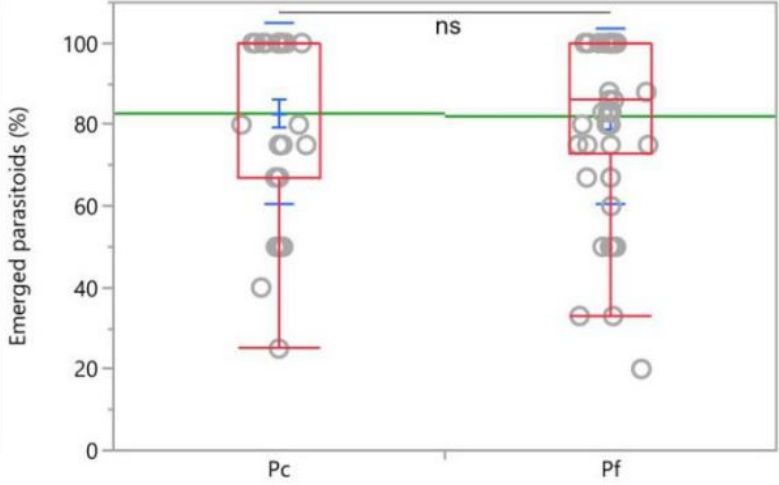

(b)
Host

Figure 6. Parasitization (a) and emergence rates (\%) (b) of Anagyrus vladimiri on Pseudococcus comstocki (Pc) and Planococcus ficus (Pf) in no-choice tests. Parasitization rate were analyzed with Wilcoxon test $(p<0.05)$ while emerged parasitoids with Kruskal-Wallis test $(p<0.05)$. The asterisk indicates significant difference between parasitoids emerged from the two hosts, $n s=$ not significant. 


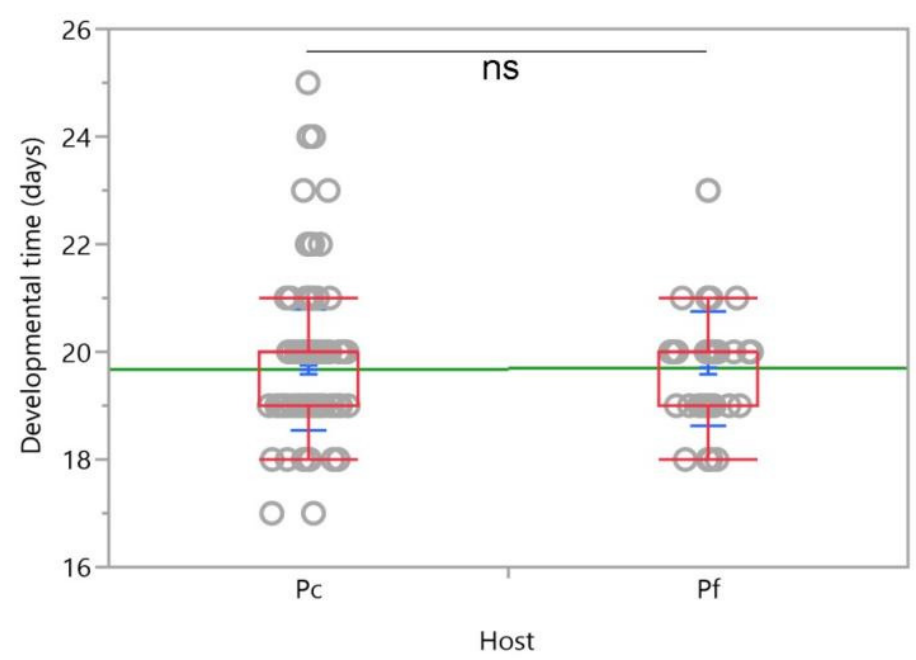

Figure 7. Developmental time of Anagyrus vladimiri from Pseudococcus comstocki (Pc) and Planococcus ficus (Pf). Each box plot indicates the median (central line) and its range of dispersion (lower and upper quartiles and outliers); green lines indicate the means, while light blue T-bars indicate standard errors; $n s=$ not significant difference in development time between parasitoids emerged from the two hosts (Kruskal-Wallis test, $p>0.05$ ).

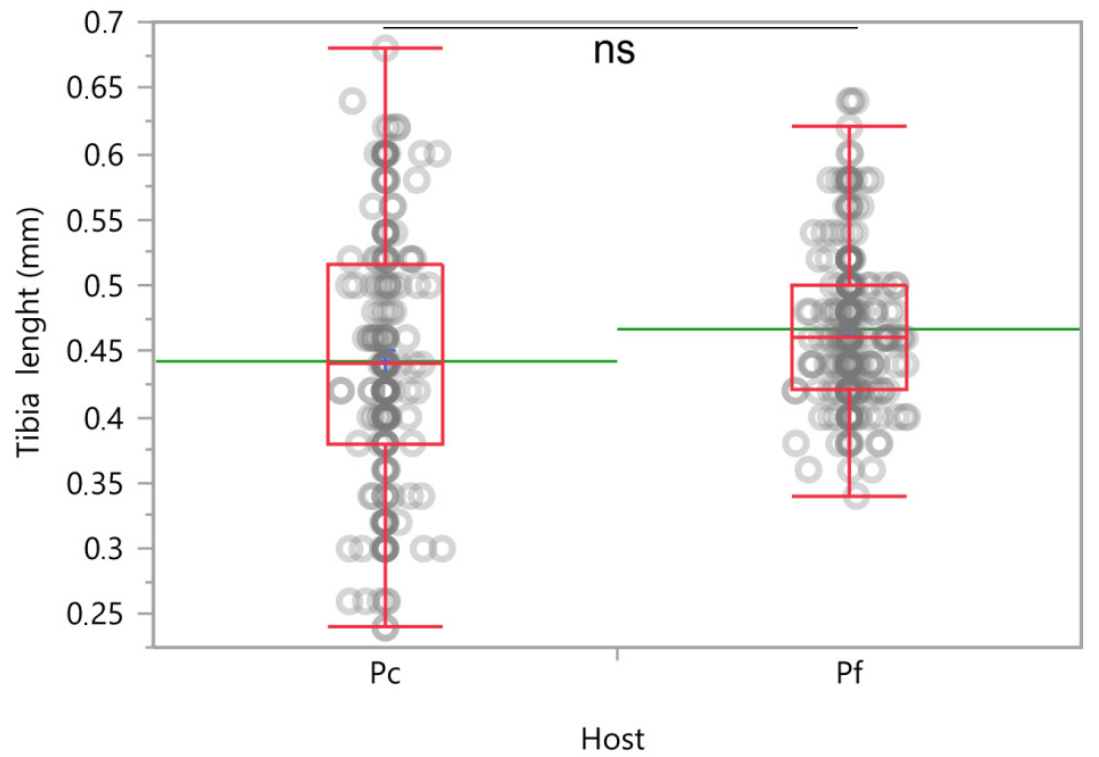

Figure 8. Hind tibia length of Anagyrus vladimiri emerged from Pseudococcus comstocki (Pc) and Planococcus ficus (Pf). Each box plot indicates the median (central line) and its range of dispersion (lower and upper quartiles and outliers); green lines indicate the means; ns = no significant difference in tibia length of parasitoids emerged from different hosts (GLZ, $p>0.05)$.

\subsection{Two-Choice Tests}

Anagyrus vladimiri did not show a significant preference for $P$. comstocki over P. ficus in terms of first parasitization choice (23 vs. 27 first choices on P. comstocki and P. ficus, respectively, $\left.\chi^{2}=0.340, d . f .=1, p=0.560\right)$. However, A. vladimiri successfully parasitized more $P$. comstocki over $P$. ficus within the observation time $(20 \mathrm{~min})\left(\chi^{2}=4.101, d . f .=1\right.$, $p=0.042$ ) (Figure 9a), but this difference was not confirmed after a $24 \mathrm{~h}$ exposure period of A. vladimiri to the mixed population of both mealybug hosts $\left(\chi^{2}=0.3440, d . f .=1, p=0.558\right)$ (Figure 9b). 


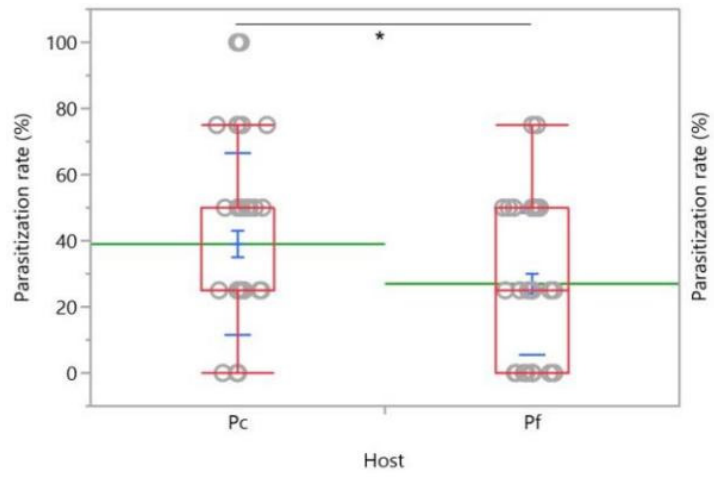

(a)

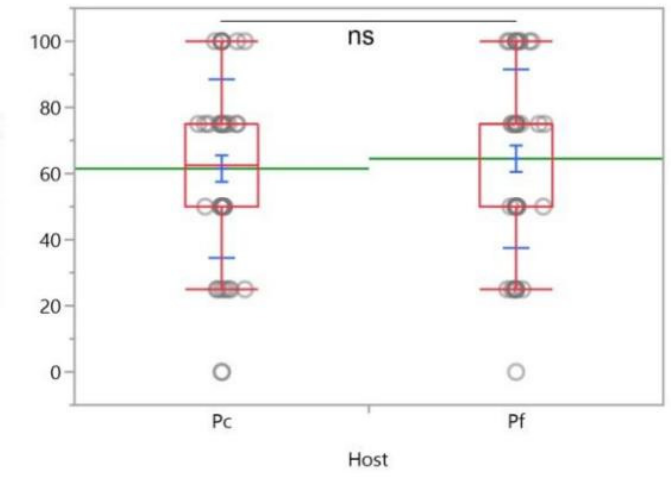

(b)

Figure 9. Parasitization rates of Anagyrus vladimiri on Pseudococcus comstocki (Pc) and Planococcus ficus (Pf) during a twochoice direct observation lasting $20 \mathrm{~min}$ (a), and after a 24 h-exposure period of the mixed mealybug population ( $4+4$ young females) to the parasitoid (b). Each box plot indicates the median (central line) and its range of dispersion (lower and upper quartiles, and outliers); green lines indicate the means, while light blue T-bars indicate standard errors. The asterisk indicates a significant difference (Wilcoxon test, $p<0.05$ ); $\mathrm{ns}=$ not significant.

The oviposition duration of $A$. vladimiri on $P$. comstocki was not different from that recorded on P. ficus $\left(\chi^{2}=0.002\right.$, d.f. $\left.=1, p=0.964\right)$ (Figure 10).

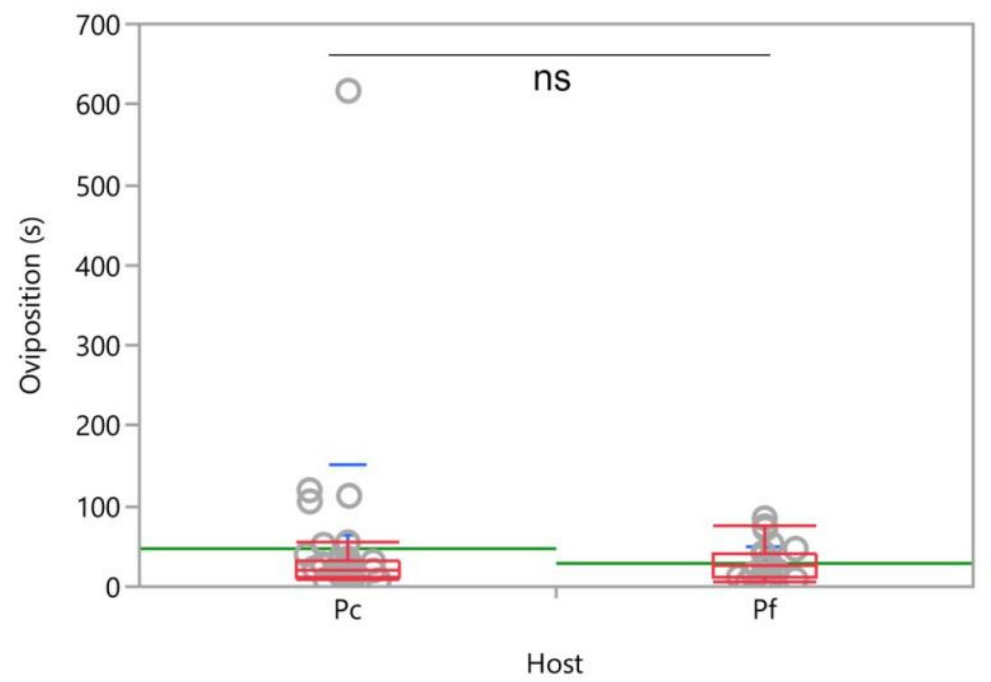

Figure 10. Oviposition duration of Anagyrus vladimiri in two-choice 20-min tests evaluating host preferences for Pseudococcus comstocki (Pc) vs. Planococcus ficus (Pf). Each box plot indicates the median (central line) and its range of dispersion (lower and upper quartiles an and outliers); green lines indicate the means, while light blue T-bars indicate standard errors; ns = not significant, it indicates the lack of significant differences (Kruskal-Wallis test, $p>0.05$ ).

\section{Discussion}

This study aimed to understand whether $A$. vladimiri could be used to effectively manage $P$. comstocki based on the knowledge that this wasp is a reliable parasitoid of $P$. ficus [12,25]. However, there was no evidence about the suitability of $P$. comstocki as a host for $A$. vladimiri, despite the growing importance of Comstock mealybugs [2]. The present study proved the successful development of $A$. vladimiri on P. comstocki. An accurate comparison between the two hosts was provided by the parasitization rate and supported by the quantification of frequencies and durations of the characteristic behaviors involved in the host location and parasitization sequence (i.e., host searching, encounter, antennal tapping, probing, oviposition, host dragging, kicking, and superparasitization). Although some displays were more frequent or prolonged on one host species over the other, the 
parasitization rates as well as the percentage of parasitoids emerged from the respective hosts, were fully comparable. Earlier research on closely related Anagyrus species showed comparable parasitization rates on different hosts of agricultural importance. For example, testing Anagyrus kamali Moursi (Hymenoptera: Encyrtidae) on Maconellicoccus hirsutus (Green) (Hemiptera: Pseudococcidae), [26] a parasitization rate of $65 \%$ was found, while Aenasius bambawalei Hayat (Hymenoptera: Encyrtidae) parasitized 52\% of Phenacoccus solenopsis Tinsley (Hemiptera: Pseudococcidae) [27]. However, concerning the emergence rate, Sagarra and Vincent [26] found much lower values than ours (between 19\% and 48.5\% depending on the age of the host), while Zhang et al. [27] obtained an emergence rate $(81.78 \%)$ similar to our results. Of note, in our study, the number of males emerged from P. ficus was higher than females.

A key feature when assessing host suitability is the evaluation of the fitness of the parasitoid progeny. As stressed by Sagarra et al. [19], body length and hind tibia length are linearly related, thus the hind tibia length can be a precise and rapid tool to evaluate the overall size of the parasitoid and, therefore, its fitness. In our results, the tibia length of A. vladimiri progeny emerged from the two host species was not statistically different, showing that the fitness of the newly emerged parasitoids was not compromised when $P$. comstocki was exploited as a host. Of note, the two-choice tests carried out by introducing mated A. vladimiri in the arena with a mixed population of four $P$. comstocki and four $P$. ficus young females revealed no preferences for a particular host, thus confirming that the parasitoid accepted both hosts. The parasitization rate of the two species after $24 \mathrm{~h}$ of host exposure to the female wasp was similar as well.

The capability of A. vladimiri to successfully parasitize different species of invasive mealybugs makes it a highly adaptable BCA. On the other hand, this may represent a relative risk of high likelihood of non-target effects if the insect needs to be introduced in regions where it is not native $[28,29]$. However, since $A$. vladimiri is naturally present in many fruit-producing regions worldwide [11,12], mass releases may boost the local population of the parasitoid, positively enhancing IPM and biocontrol programs.

This is confirmed by our results, as well as by other papers where this encyrtid has been evaluated against various mealybugs, e.g., P. ficus, Planococcus citri (Risso), Pseudococcus calceolariae (Maskell), Pseudococcus viburni (Signoret), and Phenacoccus peruvianus Granara de Willink (Hemiptera: Pseudococcidae) [30]. For instance, in this study, it is shown that A. vladimiri can complete its development on all the hosts although with different success rates. Further tests have shown significant differences in the behavioral patterns of host recognition, host handling, and the level of host acceptance [31]. In our research, the lack of differences in the sequence of events leading to oviposition, the main behavioral parameters as well as to the parasitization success in all the performed tests, support the use of $A$. vladimiri as effective BCA for $P$. comstocki management. Moreover, the utilization of both species suggests that $A$. vladimiri can be released to manage the infestation of a single mealybug pest, as well as in scenarios where both mealybug species are present simultaneously. This is a common situation in many fruit orchards of North and Central Italy (G. Benelli, pers. observ.).

\section{Conclusions}

Our no-choice experiments showed several differences in the frequency and duration of selected displays characterizing the host-seeking and oviposition of A. vladimiri on $P$. comstocki and $P$. ficus. However, both mealybug species were equally suitable as hosts for $A$. vladimiri and supported the production of progeny with similar body size. Furthermore, the results from two-choice tests highlighted that $P$. comstock $i$ was preferred by $A$. vladimiri females in a comparable manner to its classic host $P$. ficus. Overall, our findings showed that A. vladimiri successfully parasitized and developed on P. comstocki, therefore, highlighting that this encyrtid species may have general utility in biological control programs with one or more mealybug species. 
Author Contributions: Conceptualization, G.B., methodology, R.R., V.Z., D.M., F.D.G., A.C., A.L., G.B.; software, R.R., V.Z., A.C., G.B.; validation, A.C., L.-S.Z., A.L., G.B.; formal analysis, R.R., A.C., L.-S.Z., A.L., G.B.; investigation, R.R., V.Z., D.M., F.D.G., F.C., G.B.; resources, A.C., A.L., G.B.; data curation, R.R., V.Z., D.M., F.D.G., F.C., G.B.; writing-original draft preparation, R.R., A.L., G.B.; writing-review and editing, R.R., V.Z., D.M., F.D.G., F.C., A.C., L.-S.Z., A.L., G.B.; visualization, R.R., V.Z., D.M., F.D.G., F.C., A.C., L.-S.Z., A.L., G.B.; supervision, A.C., L.-S.Z., A.L., G.B.; project administration, G.B.; funding acquisition, A.L., G.B. All authors have read and agreed to the published version of the manuscript.

Funding: This study has been partially funded by Bioplanet (Cesena, Italy), a company that sells biological control agents, including $A$. vladimiri (research agreement with DAFE, UNIPI 2019). The study is not biased by this association. The company had no role in the design of the study; in analyses or interpretation of data; in the writing of the manuscript, or in the decision to publish the results.

Institutional Review Board Statement: Not applicable.

Data Availability Statement: Data are contained within the article.

Acknowledgments: The authors are thankful to Roberto Canovai and Luca Baldaccini (University of Pisa, Italy) for their kind assistance during the mealybug mass-rearing and the parasitization experiments. The authors are grateful to Stefano Foschi, Marco Mosti and Luca Marzocchi (Bioplanet, Cesena, Italy) for providing the A. vladimiri and P. comstocki individuals to start our mass-rearing.

Conflicts of Interest: The authors declare no conflict of interest.

\section{References}

1. Wan, H.H.; Song, B.Z.; Tang, G.B.; Zhang, J.; Yao, Y.C. What are the effects of aromatic plants and meteorological factors on Pseudococcus comstocki and its predators in pear orchards? Agrofor. Syst. 2015, 89, 537-547. [CrossRef]

2. Pellizzari, G.; Duso, C.; Rainato, A.; Pozzebon, A.; Zanini, G. Phenology, ethology and distribution of Pseudococcus comstocki, an invasive pest in northeastern Italy. Bull. Insect. 2012, 65, 209-215.

3. Mazzeo, G.; Longo, S.; Pellizzari, G.; Porcelli, F.; Suma, P.; Russo, A. Exotic scale insects (Coccoidea) on ornamental plants in Italy: A never-ending story. Acta Zool. Bulg. 2014, 6, 55-61.

4. Guerrieri, E.; Pellizzari, G. Parasitoids of Pseudococcus Comstocki in Italy Clausenia purpurea and Chrysoplatycerus splendens First Records from Europe. Bull. Insect. 2009, 62, 179-182.

5. Negishi, T.; Ishiwatari, T.; Asano, S. Sex pheromone of the Comstock mealybug, Pseudococcus comstocki Kuwana; bioassay method, male response-habits to the sex pheromone. Jpn. J. Appl. Entomol. Zool. 1980, 24, 1-5. [CrossRef]

6. Sawamura, N.; Narai, Y. Effect of temperature on development and reproductive potential of two mealybug species Planococcus kraunhiae (Kuwana) and Pseudococcus comstocki (Kuwana) (Homoptera: Pseudococcidae). Jpn. J. Appl. Entomol. Zool. 2008. [CrossRef]

7. Xu, P.; Xu, Z.; Li, S.; Xu, W.; Li, H.; Sheng, X.; Jin, W.; Wang, Y.; Zhao, Y. Life table of the experimental population of Comstock mealybug, Pseudococcus comstocki (Hemiptera: Pseudococcidae), at different temperatures. Acta Entomol. Sin. 2012, 55, $1362-1367$.

8. Jeon, H.Y.; Kim, D.S.; Cho, M.R.; Chang, Y.D.; Yiem, M.S. Temperature-dependent Development of Pseudococcus comstocki. Korean J. Appl. Entomol. 2004, 42, 43-51.

9. Kairo, M.T.K.; Paraiso, O.; Gautam, R.D.; Peterkin, D.D. Cryptolaemus montrouzieri (Mulsant) (Coccinellidae: Scymninae): A review of biology, ecology, and use in biological control with particular reference to potential impact on non-target organisms. CAB Rev. 2013, 8, 1-20. [CrossRef]

10. Malausa, T.; Delaunay, M.; Fleisch, A.; Groussier-Bout, G.; Warot, S.; Crochard, D.; Guerrieri, E.; Delvare, G.; Pellizzari, G.; Kaydan, M.B. Investigating biological control agents for controlling invasive populations of the mealybug Pseudococcus comstocki in France. PLoS ONE 2016, 11, e0157965. [CrossRef]

11. Andreason, S.A.; Triapitsyn, S.V.; Perring, T.M. Untangling the Anagyrus pseudococci species complex (Hymenoptera: Encyrtidae), parasitoids of worldwide importance for biological control of mealybugs (Hemiptera: Pseudococcidae): Genetic data corroborates separation of two new, previously misidentified species. Biol. Control 2019, 129, 65-82.

12. Lucchi, A.; Benelli, G. Towards pesticide-free farming? Sharing needs and knowledge promotes Integrated Pest Management. Environ. Sci. Pollut. Res. 2018, 25, 13439-13445. [CrossRef]

13. Van Driesche, R.G.; Bellotti, A.; Herrera, C.J.; Castillo, J.A. Host preferences of two encyrtid parasitoids for the Columbian Phenacoccus spp. of cassava mealybugs. Entomol. Exp. Appl. 1987, 43, 261-266. [CrossRef]

14. Romano, D.; Stefanini, C.; Canale, A.; Benelli, G. Artificial blood feeders for mosquito and ticks-Where from, where to? Acta Trop. 2018, 183, 43-56. [CrossRef] [PubMed]

15. Islam, K.S.; Copland, M.J.W. Host preference and progeny sex ratio in a solitary koinobiont mealybug endoparasitoid, Anagyrus pseudococci (Girault), in response to its host stage. Biocontrol Sci. Technol. 1997, 7, 449-456. [CrossRef] 
16. Chong, J.-H.; Oetting, R.D. Specificity of Anagyrus sp. nov. nr. sinope and Leptomastix dactylopii for six mealybug species. BioControl 2007, 52, 289-308. [CrossRef]

17. Romano, D.; Kavallieratos, N.G.; Athanassiou, C.G.; Stefanini, C.; Canale, A.; Benelli, G. Impact of geographical origin and rearing medium on mating success and lateralization in the rice weevil, Sitophilus oryzae (L.) (Coleoptera: Curculionidae). J. Stored Prod. Res. 2016, 69, 106-112. [CrossRef]

18. Bokononganta, A.H.; Neuenschwander, P.; Vanalphen, J.J.M.; Vos, M. Host stage selection and sex allocation by Anagyrus mangicola (Hymenoptera: Encyrtidae), a parasitoid of the mango mealybug, Rastrococcus invadens (Homoptera: Pseudococcidae). Biol. Control 1995, 5, 479-486. [CrossRef]

19. Sagarra, L.A.; Vincent, C.; Stewart, R.K. Suitability of nine mealybug species (Homoptera: Pseudococcidae) as hosts for the parasitoid Anagyrus kamali (Hymenoptera: Encyrtidae). Fla. Entomol. 2001, 84, 112-116. [CrossRef]

20. Benelli, G.; Desneux, N.; Romano, D.; Conte, G.; Messing, R.H.; Canale, A. Contest experience enhances aggressive behaviour in a fly: When losers learn to win. Sci. Rep. 2015, 5, 9347. [CrossRef]

21. Benelli, G.; Romano, D.; Desneux, N.; Messing, R.H.; Canale, A. Sex differences in fighting-induced hyperaggression in a fly. Anim. Behav. 2015, 104, 165-174. [CrossRef]

22. Sokal, R.R. Single classification analysis of variance. In Biometry: The Principles and Practice of Statistics in Biological Research, 1st ed.; Rolfes, M., Ed.; W.H. Freeman and Company: New York, NY, USA, 1981; pp. 207-246.

23. Cocco, A.; da Silva, V.C.P.; Benelli, G.; Botton, M.; Lucchi, A.; Lentini, A. Sustainable management of the vine mealybug in organic vineyards. J. Pest Sci. 2021, 94, 153-185. [CrossRef]

24. Gullan, P.J.; Kosztarab, M. Adaptations in scale insects. Annu. Rev. Entomol. 1997, 42, 23-50. [CrossRef]

25. Duso, C. Bioecological study on Planococcus ficus (Sign.) in Veneto. Boll. Lab. Entomol. Agrar. Silvestri' 1989, 46, 3-20.

26. Sagarra, L.A.; Vincent, C. Influence of Host Stage on Oviposition, Development, Sex Ratio, and Survival of Anagyrus kamali Moursi (Hymenoptera: Encyrtidae), a Parasitoid of the Hibiscus Mealybug, Maconellicoccus hirsutus Green (Homoptera: Pseudococcidae). Biol. Control 1999, 15, 51-56. [CrossRef]

27. Zhang, J.; Huang, J.; Lu, Y.; Xia, T. Effects of temperature and host stage on the parasitization rate and offspring sex ratio of Aenasius bambawalei Hayat in Phenacoccus solenopsis Tinsley. PeerJ 2016, 4, e1586. [CrossRef] [PubMed]

28. Messing, R.H.; Wright, M.G. Biological control of invasive species: Solution or pollution? Front. Ecol. Environ. 2006, 4, 132-140. [CrossRef]

29. Parry, D. Beyond Pandora's box: Quantitatively evaluating non-target effects of parasitoids in classical biological control. In Ecological Impacts of Non-Native Invertebrates and Fungi on Terrestrial Ecosystems; Springer: Berlin/Heidelberg, Germany, 2008; pp. 47-58.

30. Bugila, A.A.A.; Franco, J.C.; da Silva, E.B.; Branco, M. Suitability of five mealybug species (Hemiptera, Pseudococcidae) as hosts for the solitary parasitoid Anagyrus sp. nr. pseudococci (Girault) (Hymenoptera: Encyrtidae). Biocontrol Sci. Technol. 2015, 25, 108-120. [CrossRef]

31. Bugila, A.A.A.; Branco, M.; da Silva, E.B.; Franco, J.C. Host selection behaviour and specificity of the solitary parasitoid of mealybugs Anagyrus sp. nr. pseudococci (Girault) (Hymenoptera, Encyrtidae). Biocontrol Sci. Technol. 2014, 24, 22-38. [CrossRef] 